\title{
Development of Type-2 Diabetes Mellitus is associated with Low Levels of ApoA1
}

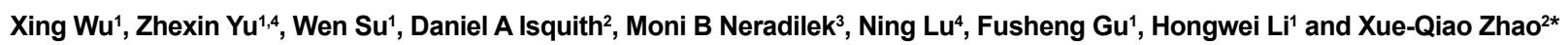

${ }^{1}$ Cardiovascular Center, Beijing Friendship Hospital, Capital Medical University, Beijing, China

${ }^{2}$ Clinical Atherosclerosis Research Lab, Division of Cardiology, University of Washington, Seattle, Washington, USA

${ }^{3}$ The Mountain-Whisper-Light Statistics, Seattle, Washington, USA

${ }^{4}$ Beijing Xihongmen Community Hospital, Beijing, China

\begin{abstract}
Aims: Type-2 diabetes mellitus (T2DM) has become a major public health crisis in China. We examined the incidence of new T2DM over 4 years for association of clinical factors and lipids with development of T2DM in a community-based population.

Methods: We included 923 Chinese subjects who participated in community-organized health checkout in both 2009 and 2013. Health history was collected; physical examination was performed; biochemistry, lipids and glucose were measured. Of 923, 819 were confirmed without T2DM in 2009 and included in the analysis.

Results: Sixty-five subjects without T2DM in 2009 were identified as having new T2DM in 2013, 8\% (65/819) over 4 years. These 65 subjects, compared to those 754 without new T2DM, were older, more likely to be male and smokers. They had higher BMI, fasting glucose, blood pressure and triglycerides, and lower levels of HDL-C and ApoA1. Multivariate logistic regression identified larger $\mathrm{BMI}(\mathrm{OR}=1.7,95 \% \mathrm{Cl} 1.22-2.39, \mathrm{p}=0.002)$, higher fasting glucose $(\mathrm{OR}=4.2,95 \% \mathrm{Cl} 2.90-6.19, \mathrm{p}<0.001)$ and low levels of $\mathrm{ApoA} 1(\mathrm{OR}=0.51,95 \% \mathrm{Cl} 0.33-0.76, p=0.002)$ were independently associated with development of T2DM over 4 years. ROC curves for new T2DM showed that AUC improved from 0.87 to 0.89 when adding ApoA 1 to the Framingham Diabetes Risk Model and from 0.85 to 0.89 when adding ApoA1 to a Chinese model.
\end{abstract}

Conclusions: This study showed a high incidence of new T2DM at $8 \%$ over 4 years among Chinese and demonstrated a significant and independent association of higher BMI and glucose levels, and lower levels of ApoA1 with development of T2DM.

Keywords: Type-2 diabetes mellitus; Apolipoproteins; Dyslipidemia; Body mass index; Population study

\section{Introduction}

Type-2 diabetes mellitus (T2DM) has become a major public health issue with strong socioeconomic impact worldwide $[1,2]$. The prevalence of T2DM in China has increased substantially over recent decades with more than 100 million Chinese people estimated to have this condition [3]. Previous studies demonstrated that the most commonly identified risk factors for development of T2DM include older age [4], positive family history of diabetes [5], higher body mass index (BMI) [4], abdominal obesity [6], smoking [7], hypertension [8], higher fasting glucose level [9], physical inactivity [10] and metabolic syndrome [11]. There have been inconsistent reports on associations of ApoA1 and HDL-C with development of T2DM [12-18]. We examined the incidence of new T2DM over 4 years for association of clinical factors and lipids with development of T2DM among Chinese subjects who participated in a community-organized health checkout in both 2009 and 2013.

\section{Material and Methods}

\section{Study population}

Among 983 subjects who participated in the community-organized health checkout in 2009 at Beijing Xihongmen Community Hospital in China, 923 had a repeat checkout in 2013. The community-organized health checkout was funded by the local government and performed by the certified health care providers. It was offered to all community members aged $\geq 18$ years. At the health checkout, health history was collected; a physical examination was performed; liver and renal functions, biochemistry, lipids and glucose were measured.

As shown in Figure 1, among the 923 subjects, 104 were identified as having T2DM or fasting glucose levels $\geq 7 \mathrm{mmol} / \mathrm{L}$ in 2009 and excluded from the study. The remaining 819 were selected for this analysis of examining risk association of development of T2DM over 4 years.

\section{Clinical evaluations and laboratory measurements}

Height $(\mathrm{m})$ and weight $(\mathrm{kg})$ were measured. BMI was calculated as weight in kilograms divided by the square of height in meters. Blood pressure (BP) was measured using an automatic manometer with an appropriate cuff size on the right arm after a resting period of $\geq 5$ minutes. Blood sample was collected after fasting for a minimum of 9 hours and subsequently analyzed for concentrations of glucose, lipids, and liver enzymes by a certified laboratory at Beijing Xihongmen Community Hospital. Renal function and other biochemistry were also measured.

${ }^{*}$ Corresponding author: Xue-Qiao Zhao, 325 9th Ave, GEC-37, Box 359720 University of Washington, Seattle, Washington, 98104, USA, Tel: 12067447305; E-mail: xueqiao@uw.edu

Received May 09, 2016; Accepted May 16, 2016; Published May 23, 2016

Citation: Wu X, Yu Z, Su W, Isquith DA, Neradilek MB, et al. (2016) Development of Type-2 Diabetes Mellitus is associated with Low Levels of ApoA1. J Diabetes Metab 7: 669. doi:10.4172/2155-6156.1000669

Copyright: @ $2016 \mathrm{Wu} \mathrm{X}$, et al. This is an open-access article distributed under the terms of the Creative Commons Attribution License, which permits unrestricted use, distribution, and reproduction in any medium, provided the original author and source are credited. 


\section{3 subjects participated in health checkout in 2009 \\ 923 subjects had repeat \\ health checkout in 2013 \\ 819 without T2DM in 2009 \\ included in the analysis}

Figure 1: Study population and selection.

\section{Definition of new T2DM}

In 2013, positive T2DM was identified using the fasting plasma glucose $(\mathrm{FPG}) \geq 7.0 \mathrm{mmol} / \mathrm{L}$ or if subjects were receiving active treatment for T2DM.

\section{Statistical analyses}

Descriptive statistics were expressed as the mean \pm SD for continuous variables and the relative frequency (\%) for categorical variables. In addition, the median and the inter-quartile range were calculated for highly skewed continuous variables. The demographic and biochemical characteristics of the study population were compared between patients with and without new T2DM using the two-sample t-test or the Wilcoxon rank sum test for continuous characteristics (the latter was used for highly skewed characteristics) and the chi-squared test for categorical characteristics. Unadjusted and adjusted logistic regression models were used to estimate the effects of biochemical characteristics on the risk of T2DM development (with the odds ratios and their $95 \%$ confidence intervals presented). Odds ratios for continuous risk factors are presented for a SDD increase. The adjusted models were adjusted for age, gender, BMI and smoking and also adjusted for multiple comparisons. Receiver operating characteristics (ROC) curves were generated to demonstrate the sensitivity and specificity of risk factors predicting development of T2DM. Area under the curve (AUC) was calculated for the model with the seven variables (age, gender, BMI, fasting glucose, blood pressure, triglycerides and HDL-C) used in Framingham Diabetes Risk Scoring Model (FDRSM) [12] and for the recently published model for rural Chinese with four variables (age, BMI, fasting glucose and triglycerides) [19] and for the adjusted models for ApoA1 or HDL-C. All statistical analyses were performed using R, version 3.1.3 (R Foundation for Statistical Computing, Vienna, Austria). A p-value of $<0.05$ was considered statistically significant.

\section{Results}

\section{Frequency of new T2DM}

Sixty-five subjects without T2DM in 2009 were identified as having new T2DM in 2013, 8\% (65/819) over 4 years.

\section{Clinical and laboratory characteristics in subjects with and without new T2DM}

As described in Table 1, the 65 subjects with new T2DM, compared to those 754 without, were more likely to be male ( $46 \%$ vs. $27 \%$, $\mathrm{p}<0.001)$ and smokers ( $38 \%$ vs. $23 \%, \mathrm{p}=0.02$ ), they were older (mean \pm SD $51 \pm 10$ vs. $47 \pm 10$ years, $\mathrm{p}=0.004)$, had larger BMI $(28.8 \pm 4.3$ vs. $\left.26.2 \pm 3.9 \mathrm{~kg} / \mathrm{m}^{2}, \mathrm{p}<0.001\right)$, higher fasting glucose levels $(5.99 \pm$ 0.67 vs. $5.17 \pm 0.53 \mathrm{mmol} / \mathrm{L}, \mathrm{p}<0.001)$ and $\mathrm{BP}(131 \pm 19$ vs. $123 \pm 17$
$\mathrm{mmHg}$ for systolic $\mathrm{BP}, \mathrm{p}=0.003 ; 86 \pm 10 \mathrm{vs} .81 \pm 11 \mathrm{mmHg}$ for diastolic BP, $\mathrm{p}<0.001$ ), also had higher ALT and creatinine levels in 2009. Interestingly, HDL-C and ApoA1 in 2009 were significantly lower in subjects with new T2DM than those without in 2013 ( $1.4 \pm 0.3$ vs. 1.5 $\pm 0.4 \mathrm{mmol} / \mathrm{L}, \mathrm{p}<0.001)$ and $(1.3 \pm 0.2$ vs. $1.4 \pm 0.3 \mathrm{mmol} / \mathrm{L}, \mathrm{p}<0.001)$. Triglycerides were higher $(2.0 \pm 1.1$ vs. $1.6 \pm 1.2 \mathrm{mmol} / \mathrm{L}, \mathrm{p}<0.001)$, while total-C, LDL-C and ApoB did not differ significantly (5.0 \pm 1.1 vs. $4.8 \pm 0.9 \mathrm{mmol} / \mathrm{L}, \mathrm{p}=0.2),(2.7 \pm 1.1$ vs. $2.5 \pm 0.8 \mathrm{mmol} / \mathrm{L}, \mathrm{p}=0.14)$ and $(0.9 \pm 0.2$ vs. $0.8 \pm 0.2 \mathrm{mmol} / \mathrm{L}, \mathrm{p}=0.2)$ (Table 1$)$.

\section{Factors associated with development of T2DM}

Unadjusted logistic regression analysis showed that blood pressure, fasting glucose levels, renal function, liver enzyme, triglycerides, HDL-C and apoA1 were significantly associated with new T2DM whereas TC, LDL-C, and ApoB were not as shown in Table 2. However, after adjustment for age, gender, $\mathrm{BMI}$ and smoking, only fasting glucose $(\mathrm{OR}=3.99,95 \% \mathrm{CI} 2.82-5.84, \mathrm{p}<0.001)$ and ApoA1 $(\mathrm{OR}=0.56,95 \% \mathrm{CI}$ $0.38-0.80, \mathrm{p}=0.002)$ remained statistically significantly associated with development of T2DM (Table 2).

\section{Association of ApoA1 with development of T2DM}

As presented in Table 3, multivariate logistic regression identified larger $\mathrm{BMI}(\mathrm{OR}=1.7,95 \% \mathrm{CI} 1.22-2.39, \mathrm{p}=0.002)$, higher levels of fasting glucose $(\mathrm{OR}=4.2,95 \% \mathrm{CI} 2.90-6.19, \mathrm{p}<0.001)$ and low levels of ApoA1 $(\mathrm{OR}=0.51,95 \% \mathrm{CI} 0.33-0.76, \mathrm{p}=0.002)$ were independently associated with development of T2DM over 4 years.

HDL-C, as expected, was highly correlated with ApoA1 (Pearson correlation $=0.69$ ) as shown in Figure 2. However, compared to ApoA1, HDL-C was non-statistically associated with development of T2DM (Tables 2 and 3).

Furthermore, ROC curves for multivariate models showed an AUC of 0.87 with the FDRSM model including age, gender, BMI, fasting glucose, BP, triglycerides and HDL-C, AUC improved to 0.89 when

\begin{tabular}{|c|c|c|c|}
\hline & $\begin{array}{c}\text { New T2DM (+) } \\
N=65\end{array}$ & $\begin{array}{c}\text { New T2DM (-) } \\
N=754\end{array}$ & P-value* \\
\hline Age, years, mean $\pm S D$ & $51.1 \pm 10.0$ & $47.2 \pm 10.4$ & 0.004 \\
\hline Male gender, $\%$ & $46 \%$ & $27 \%$ & $<0.001$ \\
\hline $\mathrm{BMI}, \mathrm{kg} / \mathrm{m}^{2}$, mean $\pm \mathrm{SD}$ & $28.8 \pm 4.3$ & $26.2 \pm 3.9$ & $<0.001$ \\
\hline Smoking, \% & $38 \%$ & $23 \%$ & 0.02 \\
\hline Systolic BP, mmHg, mean \pm SD & $130.6 \pm 19.1$ & $123.0 \pm 16.5$ & 0.003 \\
\hline Diastolic BP, mmHg, mean $\pm \mathrm{SD}$ & $85.7 \pm 9.5$ & $81.3 \pm 10.7$ & $<0.001$ \\
\hline $\begin{array}{l}\mathrm{ALT}, \mathrm{mg} / \mathrm{dl}, \text { mean } \pm \mathrm{SD} \\
\text { (median/IQR) }\end{array}$ & $\begin{array}{l}32.6 \pm 38.0 \\
(21 / 14)\end{array}$ & $\begin{array}{l}22.1 \pm 20.8 \\
\quad(18 / 12)\end{array}$ & $0.002^{* *}$ \\
\hline $\begin{array}{l}\text { AST, mg/dl, mean } \pm \text { SD } \\
\text { (median/IQR) }\end{array}$ & $\begin{array}{c}26.9 \pm 27.2 \\
(21 / 8)\end{array}$ & $\begin{array}{c}21.3 \pm 14.2 \\
(19 / 7)\end{array}$ & $0.2^{* *}$ \\
\hline Fasting Glucose, $\mathrm{mmol} / \mathrm{L}$ & $5.99 \pm 0.67$ & $5.17 \pm 0.53$ & $<0.001$ \\
\hline Creatinine, $\mu \mathrm{mol} / \mathrm{L}$ & $86.9 \pm 12.5$ & $82.0 \pm 13.5$ & 0.01 \\
\hline Total cholesterol, $\mathrm{mmol} / \mathrm{L}$ & $5.0 \pm 1.1$ & $4.8 \pm 0.9$ & 0.2 \\
\hline $\begin{array}{l}\text { Triglycerides, } \mathrm{mmol} / \mathrm{L} \\
\text { (median/IQR) }\end{array}$ & $\begin{array}{l}2.0 \pm 1.1 \\
(1.6 / 1.5)\end{array}$ & $\begin{array}{l}1.6 \pm 1.2 \\
(1.3 / 1.1)\end{array}$ & $<0.001^{\text {** }}$ \\
\hline LDL-C, mmol/L & $2.7 \pm 1.1$ & $2.5 \pm 0.8$ & 0.14 \\
\hline HDL-C, mmol/L & $1.4 \pm 0.3$ & $1.5 \pm 0.4$ & $<0.001$ \\
\hline ApoA1, mmol/L & $1.3 \pm 0.2$ & $1.4 \pm 0.3$ & $<0.001$ \\
\hline ApoB, mmol/L & $0.9 \pm 0.2$ & $0.8 \pm 0.2$ & 0.2 \\
\hline
\end{tabular}

*The two-sample t-test for continuous variables or the chi-squared test for categorical variables (gender and smoking), unless stated otherwise **The non-parametric Wilcoxon rank sum test $\mathrm{IQR}=$ intra-quartile range

Table 1: Comparison of baseline clinical and laboratory characteristics between subjects with and without new T2DM. 
Citation: Wu X, Yu Z, Su W, Isquith DA, Neradilek MB, et al. (2016) Development of Type-2 Diabetes Mellitus is associated with Low Levels of ApoA1. J Diabetes Metab 7: 669. doi:10.4172/2155-6156.1000669

Page 3 of 5

\begin{tabular}{|l|c|c|c|c|c|c|c|}
\hline & \multicolumn{3}{|c|}{ Unadjusted } & \multicolumn{3}{c|}{$\begin{array}{c}\text { Adjusted for age, gender, } \\
\text { BMI and smoking }\end{array}$} \\
\hline & $\mathrm{OR}^{*}$ & $95 \% \mathrm{Cl}$ & $\mathrm{P}$-value & $\mathrm{OR}^{*}$ & $95 \%$ Cl & P-value & P-value \\
\hline Systolic BP & 1.50 & $1.18,1.90$ & $<0.001$ & 1.19 & $0.87,1.60$ & 0.3 & 0.5 \\
\hline Diastolic BP & 1.48 & $1.15,1.89$ & 0.002 & 1.11 & $0.79,1.54$ & 0.5 & 0.8 \\
\hline Creatinine & 1.41 & $1.08,1.84$ & 0.01 & 1.00 & $0.64,1.54$ & 1 & 1 \\
\hline log(ALT) & 1.52 & $1.21,1.90$ & $<0.001$ & 1.37 & $0.99,1.87$ & 0.053 & 0.2 \\
\hline log(AST) & 1.32 & $1.07,1.61$ & 0.008 & 1.19 & $0.87,1.57$ & 0.3 & 0.5 \\
\hline Fasting glucose & 3.93 & $2.97,5.32$ & $<0.001$ & 3.99 & $2.82,5.84$ & $<0.001$ & $<0.001$ \\
\hline log(triglycerides) & 1.50 & $1.17,1.93$ & 0.001 & 1.25 & $0.90,1.71$ & 0.2 & 0.4 \\
\hline Total cholesterol & 1.21 & $0.95,1.52$ & 0.11 & 1.00 & $0.75,1.33$ & 1 & 1 \\
\hline LDL cholesterol & 1.23 & $0.97,1.55$ & 0.07 & 1.02 & $0.77,1.34$ & 0.9 & 1 \\
\hline HDL cholesterol & 0.57 & $0.42,0.75$ & $<0.001$ & 0.71 & $0.48,1.01$ & 0.06 & 0.2 \\
\hline ApoA1 & 0.48 & $0.35,0.64$ & $<0.001$ & 0.56 & $0.38,0.80$ & 0.002 & 0.01 \\
\hline ApoB & 1.22 & $0.96,1.53$ & 0.1 & 1.02 & $0.75,1.35$ & 0.9 & 1 \\
\hline
\end{tabular}

*Odds are presented per 1 SD increase in the independent variable.

${ }^{* *}$ Adjustment for multiple comparisons using the FDR method.

Table 2: Unadjusted and adjusted models for new T2DM predicted by clinical and laboratory variables in Table 1.

\begin{tabular}{|l|c|c|c|}
\hline $\begin{array}{l}\text { A. Model with age, gender, BMI, } \\
\text { smoking, fasting glucose and ApoA1 }\end{array}$ & OR & $\mathbf{9 5 \%}$ Cl & P-value \\
\hline Age, per 1 SD & 0.98 & $0.68,1.41$ & 0.9 \\
\hline Male gender & 1.53 & $0.62,3.75$ & 0.3 \\
\hline BMI, per 1 SD & 1.70 & $1.22,2.39$ & 0.002 \\
\hline Smoking (+) & 2.07 & $0.83,5.16$ & 0.12 \\
\hline Fasting glucose, per 1 SD & 4.16 & $2.90,6.19$ & $<0.001$ \\
\hline Apo A1, per 1 SD & 0.51 & $0.33,0.76$ & 0.002 \\
\hline $\begin{array}{l}\text { B. Model with age, gender, BMI, } \\
\text { smoking, fasting glucose and HDL-C }\end{array}$ & & & \\
\hline Age, per 1 SD & 0.99 & $0.68,1.43$ & 0.9 \\
\hline Male gender & 1.77 & $0.71,4.43$ & 0.2 \\
\hline BMI, per 1 SD & 1.68 & $1.21,2.35$ & 0.002 \\
\hline Smoking (+) & 1.82 & $0.73,4.53$ & 0.2 \\
\hline Fasting glucose, per 1 SD & 3.95 & $2.79,5.79$ & $<0.001$ \\
\hline HDL-C, per 1 SD & 0.72 & $0.47,1.09$ & 0.13 \\
\hline
\end{tabular}

Table 3: Multivariate logistic regression models for new T2DM $(\mathrm{N}=646)$.

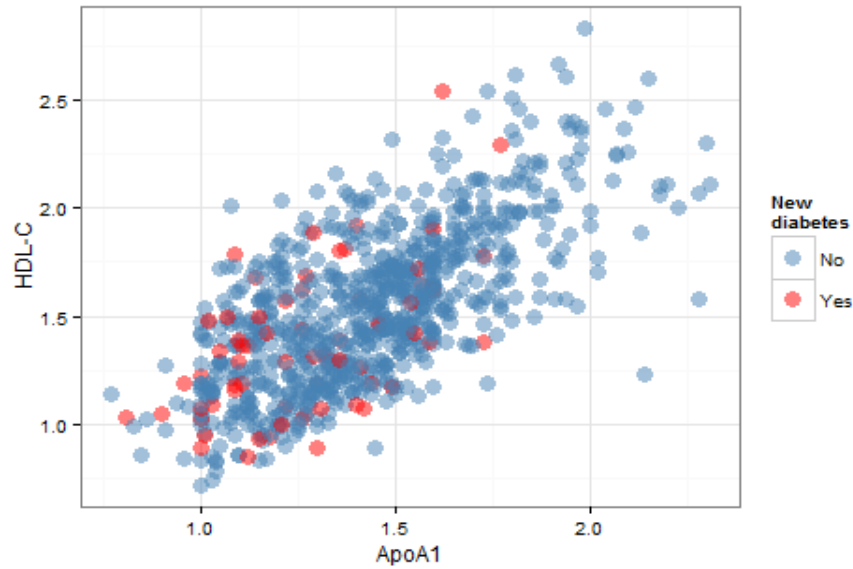

Figure 2: Apo A1 vs. HDL-C by new diabetes status. Pearson correlation = $0.69, p<0.001$.

adding ApoA1 to the model (Figure 3A). Similarly, when ApoA1 was added to the Chinese model including age, BMI, fasting glucose and triglycerides, the AUC improved from 0.85 to 0.89 , however, AUC only increased to 0.87 when adding HDL-C to the model (Figure $3 \mathrm{~B}$ ).

\section{Discussion}

Type-2 diabetes mellitus has become a major public health crisis in China with rapid urbanization, decreased physical activity, unhealthy diet and many other social and environmental factors [2,3]. In our community-based urban population, conservatively, $8 \%$ was found to have new T2DM over 4 years. This incidence was higher than $5.8 \%$ over 7.7 years In the PREVEND study [19], 6.9\% over 4 years in healthy Korean men [20], 4.3\% over 5 years in male Japanese workers [21] and $6 \%$ over 6 years among rural Chinese [19]. The higher incidence of new T2DM seen in this study is consistent with the overall substantial increase in the prevalence of T2DM in China [3].

Similar to that identified in the previous studies, older age, male gender, smoking, larger BMI, higher blood pressure, higher fasting glucose level and dyslipidemia with high triglycerides and low levels of HDL or ApoA1 were associated with new T2DM [4-11], however, after adjustment for age, gender, BMI and smoking, only fasting glucose and ApoA1 remained a statistically significant association
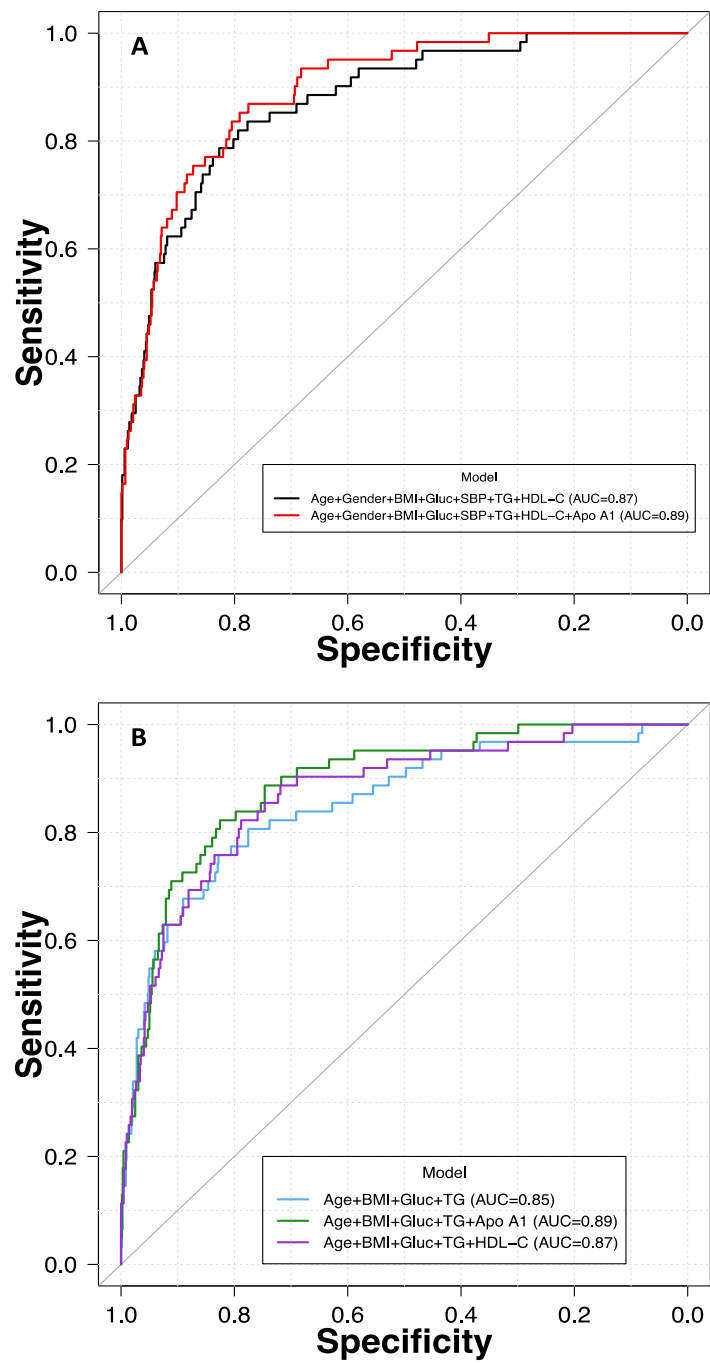

Figure 3: ROC curves for multivariate models for new T2DM. Panel A: black line represents the FDRSM model with $A U C=0.87$; red line for adding $A p o A 1$ to the model with UAC $=0.89$. Panel $\mathrm{B}$ : The recently published Chinese model in blue with $A \cup C=0.85 ; A U C$ improved to 0.89 when adding $A p o A 1$ to the model in green, and to 0.87 when adding HDL-C in purple. 
with development of T2DM. Furthermore, multivariate analysis showed that higher BMI, increased fasting glucose levels and lower levels of ApoA1 were significantly and independently able to predict new onset of T2DM over 4 years in our study. We found that each SD (approximately $0.55 \mathrm{mmol} / \mathrm{L}$ ) higher in fasting glucose levels increase the risk of developing T2DM by more than 4 folds $(\mathrm{OR}=4.2,95 \% \mathrm{CI}$ 2.90-6.19, $\mathrm{p}<0.001$ ), and each SD (approximately $4 \mathrm{~kg} / \mathrm{m}^{2}$ ) increase in BMI almost doubled the risk $(\mathrm{OR}=1.7,95 \% \mathrm{CI} 1.22-2.39, \mathrm{p}=0.002)$. These results strongly support the importance of weight and glucose control through exercise and a healthy diet in prevention of T2DM in a community-based population.

Our study demonstrated that each SD $(0.25 \mathrm{mmol} / \mathrm{L})$ decrease in ApoA1 independently led to a 97\% increased risk of new T2DM $(\mathrm{OR}=1 / 0.51=1.97, \mathrm{p}=0.002)$ over 4 years among the communitybased urban Chinese subjects who are relatively healthy and without multiple risk factors for T2DM. However, this association has not been found to be consistent in previous studies [22-25] although previous research suggested that ApoA1 affects glucose metabolism via multiple mechanisms, including enhanced insulin secretion [26], increased insulin-independent glucose uptake in muscle and adipose tissues [27,28], improved insulin sensitivity [29], and reversed adipocyte dysfunction [30] and restored adiponectin expression and insulin sensitivity [31] with ApoA1 mimetic peptide. Furthermore, genetic studies suggested that genetic variation in ABCA1 has been associated with the increased risk of T2DM [32], and one study suggested that loss-of-function mutations in ABCA1 were associated with impaired b-cell function, but not with the development of T2DM [33]. Further investigations in both prospective population based studies and mechanistic basic science research including genetic studies are needed to confirm and establish the roles that ApoA1 plays in development of T2DM.

Our study also found that HDL-C, compared to ApoA1, had a much weaker association with development of T2DM although HDL-C is closely correlated with ApoA1. The data presented in Table 3 and Figure $3 \mathrm{~B}$ indicated that HDL-C should not be considered as a substitute for ApoA1 in risk prediction for new T2DM. In addition to a growing body of evidence suggesting that HDL-C concentration does not accurately reflect the heterogeneous HDL particles and the HDL's vascular protective function [34,35], a recently published Mendelian randomization study [18] showed that low levels of HDL-C due to genetic variation do not increase risk of T2DM in the general population, which suggesting that the previously observed association between low levels of HDL-C and development of T2DM may be due to reverse causation of a state of prediabetes [18]. Similarly, a Mendelian randomization study showed that raised triglyceride levels were not causally associated with the risk of T2DM [36]. These results together indicate that the dyslipidemia with low HDL-C and high triglycerides has existed long before clinical diagnosis of T2DM and question HDL-C increasing therapy for reducing risk of new T2DM.

Furthermore, ApoA1 appeared to improve the risk prediction of new T2DM comparing to the existing risk prediction models. In the FDRSM model including age, gender, BMI, fasting glucose, BP, triglycerides and HDL-C [12], AUC improved from 0.87 to 0.89 when adding ApoA1 to the model (Figure $3 \mathrm{~A}$ ). In the recently published Chinese model including age, BMI, fasting glucose and triglycerides [19], AUC improved from 0.85 to 0.89 when adding ApoAl to the model (Figure 3B).

Statistically, developing a multivariate logistic regression model requires at least 20 events per independent variable [37]. Others have argued for a less strict rule that 10 events per independent variable would be sufficient [38]. Our analysis included 5 independent variables for a total of 65 subjects with new T2DM (13 events per independent variable), which is adequate by the less strict rule. In order to confirm the reliability of the estimated odds ratios and their confidence intervals and p-values, we performed a sensitivity analysis for the multivariate models in Table 3 that used models with only 3 independent variables (adjustments for the relatively weaker effects of age, gender and smoking were excluded) following the stricter rule. The results of the sensitivity analysis showed virtually unchanged estimate of the ApoA1 and HDL-C effects and supporting our confidence in the results shown in Table 3.

\section{Limitation}

Hemoglobin A1C was not measured and oral glucose tolerance test was not performed in our study, which may result in an underestimation the true incidence of new T2DM over 4 years. Also, data on parental history of T2DM was not collected. Nevertheless, our analysis including the community-based urban population who participated in healthcheck up demonstrated an alarming rate of new T2DM, and higher BMI, increased fasting glucose levels and lower levels of ApoA1 were independently associated with development of T2DM among Chinese living in Beijing.

\section{Conclusions}

In conclusion, our analysis showed a high incidence of new type2 diabetes at $8 \%$ over 4 years among middle aged urban Chinese and demonstrated a significant and independent association of larger BMI, higher fasting glucose levels and lower levels of ApoA1 with future development of type- 2 diabetes. Future prospective studies are needed to investigate the roles that ApoA1 may play in the development of type-2 diabetes.

\section{Funding Source}

The analysis was partially supported by the Beijing Natural Science Foundation (Grant No. 7144204).

\section{References}

1. World Health Organization (2014) Global Health Estimates: Deaths by Cause, Age, Sex and Country, 2000-2012. Geneva, World Health Organization.

2. Chinese Diabetes Society (2014) China Guideline for Type 2 Diabetes. China J Endocrinol Metab 30: 893-942.

3. Chan JCN, Zhang Y, Ning G, Ma RCW, Lin X, et al. (2014) Diabetes in China a societal solution for a personal challenge. Early therapy for type 2 diabetes in China. Lancet Diabetes \& Endocrinology

4. Menke A, Rust KF, Fradkin J, Cheng YJ, Cowie CC (2014) Associations between trends in race/ethnicity, aging, and body mass index with diabetes prevalence in the United States: a series of cross-sectional studies. Ann Intern Med 161: 328.

5. Meigs JB, Cupples LA, Wilson PW (2000) Parental transmission of type 2 diabetes: the Framingham Offspring Study. Diabetes 49: 2201-2207.

6. Mokdad AH, Ford ES, Bowman BA, Dietz WH, Vinicor F, et al. (2003) Prevalence of obesity, diabetes, and obesity-related health risk factors, 2001. JAMA 289: 76-79.

7. Willi C, Bodenmann P, Ghali WA, Faris PD, Cornuz J (2007) Active smoking and the risk of type 2 diabetes: a systematic review and meta-analysis. JAMA 298: 2654-2664

8. Gress TW, Nieto FJ, Shahar E, Wofford MR, Brancati FL (2000) Hypertension and antihypertensive therapy as risk factors for type 2 diabetes mellitus. Atherosclerosis Risk in Communities Study. N Engl J Med 342: 905-912.

9. Nichols GA, Hillier TA, Brown JB (2008) Normal fasting plasma glucose and risk of type 2 diabetes diagnosis. Am J Med 121: 519-524. 
Citation: Wu X, Yu Z, Su W, Isquith DA, Neradilek MB, et al. (2016) Development of Type-2 Diabetes Mellitus is associated with Low Levels of ApoA1. J Diabetes Metab 7: 669. doi:10.4172/2155-6156.1000669

Page 5 of 5

10. Grøntved A, Hu FB (2011) Television viewing and risk of type 2 diabetes, cardiovascular disease, and all-cause mortality: a meta-analysis. JAMA 305: 2448-2455.

11. Ford ES, Li C, Sattar N (2008) Metabolic syndrome and incident diabetes: current state of the evidence. Diabetes Care 31: 1898-1904.

12. Wilson PW, Meigs JB, Sullivan L, Fox CS, Nathan DM, et al. (2007) Prediction of incident diabetes mellitus in middle-aged adults: the Framingham Offspring Study. Arch Intern Med 167: 1068-1074.

13. von Eckardstein A, Schulte H, Assmann G (2000) Risk for diabetes mellitus in middle-aged Caucasian male participants of the PROCAM study: implications for the definition of impaired fasting glucose by the American Diabetes Association. Prospective Cardiovascular Munster. Journal of Clinical Endocrinology and Metabolism 85: 3101-3108.

14. Onat A, Hergenc G, Bulur S, Ugur M, Kucukdurmaz Z, et al. (2010) The paradox of high apolipoprotein A-I levels independently predicting incident type-2 diabetes among Turks. International Journal of Cardiology 142: 72-79.

15. Seo MH, Bae JC, Park SE, Rhee EJ, Park CY, et al. (2011) Association of lipid and lipoprotein profiles with future development of type 2 diabetes in nondiabetic Korean subjects: a 4-year retrospective, longitudinal study. J Clin Endocrinol Metab 96: E2050-E2054.

16. Hwang YC, Ahn HY, Kim WJ, Park CY, Park SW (2012) Increased apoB/Aratio independently associated with type 2 diabetes mellitus: crosssectional study in a Korean population. Diabetic Medicine 29:1165-1170.

17. Abbasi A, Corpeleijn E, Ron T, Gansevoort, Rijk O, et al. (2013) Role of HDL Cholesterol and Estimates of HDL Particle Composition in Future Developmen of Type 2 Diabetes in the General Population: The PREVEND Study. J Clin Endocrinol Metab 98: E1352-E1359.

18. Haase CL, Tybjærg-Hansen A, Nordestgaard BG, Frikke-Schmidt R (2015) HDL Cholesterol and Risk of Type 2 Diabetes: A Mendelian Randomization Study. Diabetes 64: 3328-3333.

19. Zhang M, Zhang H, Wang C, Ren Y, Wang B, et al. (2016) Development and Validation of a Risk-Score Model for Type 2 Diabetes: A Cohort Study of a Rural Adult Chinese Population. PLoS ONE 11: e0152054.

20. Jung CH, Lee MJ, Kang YM, Hwang JY, Jang JE, et al. (2014) Higher serum bilirubin level as a protective factor for the development of diabetes in healthy Korean men: A 4 year retrospective longitudinal study Metabolism. Clinical and Experimental 63: 87-93.

21. Morimoto H, Sakata KM, Oishi K, Tanaka S, Nakada K, et al. (2013) Effect of high-sensitivity $\mathrm{C}$-reactive protein on the development of diabetes as demonstrated by pooled logistic-regression analysis of annual health-screening information from male Japanese workers. Diabetes \& Metabolism 39: 27-33.

22. Yi DW, Jeong DW, Lee SY, Son SM, Kang YH (2012) The Association between Apolipoprotein A-II and Metabolic Syndrome in Korean Adults: A Comparison Study of Apolipoprotein A-I and Apolipoprotein B. Diabetes Metab J 36: 56-63.

23. Wang W, Khan S, Blackett P, Alaupovic P, Lee E (2013) Apolipoproteins A-I, B, and $\mathrm{C}$-III in young adult Cherokee with metabolic syndrome with or without type 2 diabetes. J Clin Lipidol 7: 38-42.

24. Onat A, Hergenç G, Bulur S, Uğur M, Küçükdurmaz Z, et al. (2010) The paradox of high apolipoprotein A-I levels independently predicting incident type-2 diabetes among Turks. Int J Cardiol 142: 72-79.

25. Hwang YC, Ahn HY, Park SW, Park CY (2014) Association of HDL-C and apolipoprotein A-I with the risk of type 2 diabetes in subjects with impaired fasting glucose. Eur J Endocrinol 171: 137-142.

26. Stenkula KG, Lindahl M, Petrlova J, Dalla-Riva J, Göransson O, et al. (2014) Single injections of apoA-I acutely improve in vivo glucose tolerance in insulinresistant mice. Diabetologia 57: 797-800.

27. Dalla-Riva J, Stenkula KG, Petrlova J, Lagerstedt JO (2013) Discoidal HDL and apoA-I-derived peptides improve glucose uptake in skeletal muscle. J Lipid Res 54: 1275-1282.

28. Zhang Q, Zhang Y, Feng H, Guo R, Jin L, et al. (2011) High density lipoprotein $(\mathrm{HDL})$ promotes glucose uptake in adipocytes and glycogen synthesis in muscle cells. PLoS One 6: e23556.

29. McGrath KC, Li XH, Whitworth PT, Kasz R, Tan JT, et al. (2014) High density lipoproteins improve insulin sensitivity in high-fat diet-fed mice by suppressing hepatic inflammation. J Lipid Res 55: 421-430.

30. Vanella L, Li M, Kim D, Malfa G, Bellner L, et al. (2012) ApoA1: mimetic peptide reverses adipocyte dysfunction in vivo and in vitro via an increase in heme oxygenase (HO-1) and Wnt10b. Cell Cycle 11: 706-714

31. Marino JS, Peterson SJ, Li M, Vanella L, Sodhi K (2012) ApoA-1 mimetic restores adiponectin expression and insulin sensitivity independent of changes in body weight in female obese mice. Nutr Diabetes 12: e33.

32. Villarreal-Molina MT, Flores-Dorantes MT, Arellano-Campos O, VillalobosComparan M, RodrÃguez-Cruz M, et al. (2008) Metabolic Study Group. Metabolic Study Group. Association of the ATP-binding cassette transporte A1 R230C variant with early-onset type 2 diabetes in a Mexican population Diabetes 57: 509-513.

33. Vergeer M, Brunham LR, Koetsveld J, Kruit JK, Verchere CB, et al. (2010) Carriers of loss-of-function mutations in ABCA1 display pancreatic beta-cel dysfunction. Diabetes Care 33: 869-874.

34. Rohatgi A, Khera A, Berry JD, Givens EG, Ayers CR, et al. (2014) HDL cholesterol efflux capacity and incident cardiovascular events. N Engl J Med 371: 2383-2393.

35. Saleheen D, Scott R, Javad S, Zhao W, Rodrigues A (2015) Association of HDL cholesterol efflux capacity with incident coronary heart disease events: a prospective case-control study. Lancet Diabetes Endocrinol. 3: 507-513.

36. De Silva NM, Freathy RM, Palmer TM, Donnelly LA, Luan J, et al. (2011) Mendelian randomization studies do not support a role for raised circulating triglyceride levels influencing type 2 diabetes, glucose levels, or insulin resistance. Diabetes 60:1008-1018.

37. Harrell FE, Lee KL, Mark DB (1996) Multivariate prognostic models: issues in developing models, evaluating assumptions and adequacy, and measuring and reducing errors. Stat Med 15: 361-387.

38. Peduzzi P, Concato J, Kemper E, Holford TR, Feinstein AR (1996) A simulation study of the number of events per variable in logistic regression analysis. J Clin Epidemiol 49: 1373-1379. 